\title{
Does the engagement between science and society pose risks for intelligent scientific practice?
}

\author{
H LOTRIET
}

\begin{abstract}
This paper examines the interaction between science and society. Society considers these interactions as vital to understand and reduce the uncertainty of the impact of scientific activity on society. The purpose of this paper is to investigate the converse situation whether the engagement of society with scientific activity creates uncertainty (or perceived risks) in terms of scientific practice, and whether there is potential for this engagement to create tensions in terms of the intelligent nature of scientific practice. In order to achieve this, a cultural-historical, activity-based conceptualisation of intelligence is applied to scientific activity and its implications are discussed in terms of sciencesociety interactions.
\end{abstract}

Keywords: Science, society, engagement, activity theory, intelligent scientific practice

\section{Introduction}

The engagements between scientists and stakeholders from society go by many names - these include the "democratization of science", the "socialization of science" and even sometimes "postnormal science" (Turnpenny et al., 2011). These engagements have become commonplace in many parts of the developed world, for example the USA (Kleinman, 1998), the UK (Te Kulve and Rip, 2011), Belgium (Van Oudheusden, 2011), and the Netherlands (Petersen et al., 2011). The engagements have mainly centred on contentious scientific and technological issues, such as nanotechnology (Swierstra et al., 2011), environmental protection (Peterson et al., 2011), recombinant DNA, epidemiology and AIDS treatment (Kleinman, 1998), and energy policy and micro-electronics (Van Est, 2008).

The need for these engagements is rooted in society's concern that the products of science and technology that are largely ubiquitous in various aspects of societal life, are putting society at risk. These risks are not always communicated by scientists to society. Society therefore does not necessarily understand these risks, even though it has in a sense become the "object" of scientific endeavour. Societal concerns touch on a number of issues - obviously concerns for health and safety, but also socio-economic impact, environmental impact, and the ethical basis of research activity (Swierstra et al., 2011).

Society's main concern is therefore the risks associated with scientific activity. The nature and conceptualisation of these risks are complex. This emerging complexity challenges traditional views that science is predicable, controllable and calculable (Lövbrand et al., 2010). The complexity also relates to the diversity of values, contexts and perceptions in society. The

1. Prof Hugo Lotriet is the Head Research and Graduate Studies in the College of Science Engineering and Technology at the University of South Africa, Johannesburg. Email: lotrihh@unisa.ac.za 
assessment of the implications of these risks therefore cannot simply be left to the judgment of scientists (Bijker et al., 2010).

Concurrent with these societal concerns, is the loss of credibility of science in society (Lövbrand et al., 2010). Society now exhibits an attitude of "sceptical wait-and-see" rather than enthusiasm in terms of scientific endeavour (Swierstra et al., 2011). This has led to society's growing expectation that scientists should "justify their knowledge claims" to a wider audience (Lövbrand et al., 2010).

Engagements between science and society have mainly been initiated in order to enable society to understand the societal risks involved in the development of science and technological artefacts, and to collaboratively develop ethical guidelines to ensure that science does not expose society to risks that it is not willing to tolerate (see for example Bijker et al., 2007). The ideal is that these engagements will lead (at least) to expressions of the diversity of values, arguments, assumptions and meanings emanating from society that should inform science and its governance (Lövbrand et al., 2010). This expectation is partly reflected in the metaphors mentioned at the start of the paper that have science as their object.

The recent national debate about nanotechnology in the Netherlands is interesting in terms of the scale on which it was undertaken. The intention was literally to engage with as large a part of the Dutch population as possible at a national level. A brief discussion of this debate as a case study serves as a point of departure for this paper.

With the Dutch debate on nanotechnology as a point of departure, this paper examines the interaction between scientists and society in literature in order to understand how it could be conceptualised, what the associated challenges are that need to be addressed, and what the implications are for intelligent scientific activity.

The involvement of society in shaping scientific activity has become a given. This is evident from the current state of development and evolution of societal dynamics mentioned in this paper. Latour (2004) argues that the political power associated with the notion of science as accessible only by scientists (he uses the analogy of the Platonic cave) while society languishes in ignorance, does not apply anymore. There still is some evidence of scientific stakeholders clinging to the outdated conception, sometimes referred to as the "Information Deficit Model" (Van Est, 2008). In terms of the metaphor of Plato's cave as used by Latour, anyone can exit the cave and become enlightened and no one would languish in the darkness of the cave by choice. There is therefore no justification or need for society to rely on scientists as sole intermediaries for access to the sciences.

This conceptualisation of public access to the sciences creates various uncertainties (risks) in terms of understanding its implications for and impact on scientific activity. From a sociotechnical perspective it would be expected that in any interaction of substance between two domains (such as science and society), the outcome will be that both domains will be affected (and would undergo changes) as a result of the interaction.

In this instance it could be expected that both society and science would change as a result of their engagement. Literature reports quite extensively on how improved risk evaluation frameworks have enabled society to make more intelligent and informed decisions about the risks related to scientific work (see for instance Bijker 2009a and 2009b). However, it is less clear on the impact of societal engagement on scientists and their activities. This paper, written by an author who is situated within a scientific context therefore focuses on this more neglected side by reflecting on the potential implications of science-society engagement for 
science and scientific activity. Specifically, the paper reflects on the notion of intelligence and intelligent scientific activity and whether interaction between science and society has the potential to create risks (or uncertainties) related to such intelligent scientific activity. This focus relates to the theme that constitutes the context of this paper, i.e. the 2014 miniconference held around the concern that "human intelligence" is under siege and is becoming a scarce resource in academic institutions.

Within this broader concern the paper specifically focuses on scientific activity (a significant part of the activity at academic institutions) and what tensions (i.e. battles) the engagement with society could create in terms of intelligent scientific activity. Battle metaphors have indeed been used to describe science-society interactions. For example Kleinman (1998) refers to the heated debates in the nineties (especially in the USA) on who legitimately can make pronouncements on science, as the "science wars".

The paper therefore does not focus on the nature of the boundaries and boundary-crossing for the scientific domain, but on conceptualising this relatively new, but seemingly permanent arrangement of societal engagement with science. The aim is to enable a better understanding of what constitutes intelligent science-society interaction and by implication intelligent scientific activity as well as a better understanding of the potential uncertainties (i.e. risks) involved that could create tensions and conflicts. In this regard the paper proposes a culturalhistorical framework for intelligent action as a conceptual basis for intelligent scientific activity. This framework provides a lens to identify specific areas of potential conflict (battlefields) that could manifest in science-society interactions.

The paper therefore proposes conceptions of science, its role in society and a culturalhistorical notion of intelligence that enable the visualisation of tensions related to sciencesociety interactions and scientific activity. In order to do this, the paper proposes a conceptualisation that draws mainly on discourses from two disciplines - firstly, sociotechnical literature to provide a conceptualisation of science-technology interaction and secondly Activity Theory literature - essentially a continuation of Russian social psychology that has its roots in the ideas of Vygotsky (1980).

The structure of the paper is as follows. As a point of departure the paper provides a brief description of the recent national Dutch nanotechnology debate as an example of sciencesociety interaction. The paper then proceeds to discuss concepts and issues reported on in literature that relate to science-society interactions. After this, the paper focusses specifically on scientific activity and discusses how science is becoming re-conceptualised as a result of science-society interaction. The extent of potential involvement and associated modes of interaction available to society are investigated. The author proposes a cultural-historical (activity-based) notion of intelligence for use to visualise potential areas of tension and conflicts related to science-society interaction and by implication related to scientific activity.

A number of limitations to this paper need to be stated at the outset. Firstly, for the purpose of this paper the notion of science is the "harder" notion of natural sciences, engineering and technology. The paper does not attempt to engage with the interesting discourses on the narrowing of the gap between natural sciences and social sciences and humanities, although the perspectives provided by the author are mostly social and socio-technical in nature. This is because the researcher's own background is in Information Systems, which is essentially a social discipline. Secondly, the paper does not attempt to provide an exhaustive list or discussion of all instances of science-society interaction. As previously stated, the single case reported on serves only as a point of departure to arrive at a more conceptual discussion on

TD, 11(2), November 2015, Special edition, pp. 29-42. 
the nature of science-society interaction, scientific activity and intelligence. It is recognised that much richness could be added by examining other instances of science-society interaction in future research. The paper does not attempt to provide any holistic picture of either the battles for intelligence in academic institutions or contributing factors to the bigger discourses on the nature of "good" science.

\section{Point of departure: The Dutch national debate on nanotechnology}

The Dutch has a history of experimentation with social engagement with science. Some notable examples include a nuclear technology debate and a subsequent discussion around energy policy, in addition to discourses on genetic engineering and micro-electronics (Van Est, 2008).

The Commissie Maatschappelijke Dialoog Nanotechnologie (CieMDN) was created in 2009 as an independent commission with a mandate to facilitate national discourse in the Netherlands around nanotechnology. Interestingly five of the nine members (including both the chair and the vice-chair) of the commission were from Dutch Universities (Commissie Maatschappelike Dialoog Nanotechnologie, 2011). Although government initiated CieMDN on the advice of other institutions (notably the Dutch "Gezondheidsraad"), it was structured to be independent of government mainly in order to ensure a good public reputation for the body (Bijker et al., 2010).

The commission started off with a completely open agenda in terms of expected outcomes (Bijker et al. 2010, op. cit.), after which it consulted widely to establish the themes of the dialogue. An open invitation was sent to stakeholders in society for project proposals on ways to mediate the dialogue (the CieMDN did not do this themselves) (CieMDN, 2011). As resources were limited, prioritisation between projects had to be implemented in order to stay within the budget (Bijker et al., 2010).

The process could not assume informed opinions due to the early phase of development of nanotechnology. Therefore, the project was deliberately executed in phases - i.e. provision of information, awareness activities and finally discourses on nanotechnology, with the first two being considered conditions for successful execution of the third phase (Bijker et al., 2010, op. cit.).

The project that took place from March 2009 to December 2010 ultimately involved a large diversity of interest groups and used a significant variety of methods to engage with these interest groups. These included "old and new media", teaching materials for school children, theatre, art, television, exhibitions, mobile nanotechnology labs allowing citizens to interact with nanotechnology, YouTube animations, general use of the Internet for interaction (e.g. through games for the young) as well as philosophical "vignettes", debates, focus groups and workshops. The purpose of the engagements was both to inform and to get opinions of citizens (Bijker et al., 2010, op. cit.).

A core finding on the basis of this dialogue is that society is not against science, but requires science to proceed with care (CieMDN, 2011). 


\section{Conceptualisation of Science-Society interactions}

\subsection{Assumptions and historical developments}

Elements of the conceptualisation of the relationship between scientists and society derive from the ancient Greeks. Nowotny (2003) points out that Plato held strong views on the contrast between those who understand science (to be held in esteem as aristocracy) and the process of the formation of public opinion which he considered to be "mob-based" and irrational, thus by implication advocating a strong boundary between the domains of science and public opinion.

Bijker (2010) departs from the assumption that the mutual interactions between science, technology and society mean that current day societies are "thoroughly technological" and that present day technology is "pervasively cultural". He traces the notion of technological culture as the (necessary) culmination in the evolution of notions around the interaction of technology with society (starting with a single technological artefact as unit of analysis and progressing through "technological systems" and "sociotechnical ensembles" to "technological culture") (Bijker, 2010). Society has to become aware that science and technology changes the core fabric of society - practices, values, goals, etc. (Swierstra et al., 2011). Interestingly Bijker et al. (2010) even provide the example that science and technology impacts on metaphors in poetry and literature.

The notion that current society is technological is also supported by Barry (2001) who argues that this should be mainly understood as society's preoccupation with technology-related challenges. The notion of the technological society and its implications for various aspects of societal activity have indeed become a widely researched topic - see for examples Winner (1992) on democracy in a technological society, or De Raath (1997) on the humane management of organisations in a technological society.

If the nature of current societal culture is assumed to be inherently technological, it would consequently be subject to science and technology mediated vulnerability (Bijker et al., 2010). This vulnerability should not necessarily be construed as negative, but rather as inevitable and the vulnerability could refer to either society and humanity or technological systems. Indeed, vulnerability is a pre-condition for creativity and innovation (Bijker, 2009).

3.2 Reflections on the process of engagement: Pre-conditions for a successful societal dialogue

It is important to prepare stakeholders prior to engagement in order to enable a meaningful engagement (Te Kulve and Rip, 2011). This would counter any claims that the public would be unable to participate in the engagement because members of the public are uninformed (as was claimed by scientists in the past) (Kleinman, 1998). This is situated within the greater context of a general realization by many governments of a need for scientifically "empowered" citizens (Mohr, 2011). Mohr also points out that the conceptualisation of the notion of science-interaction by the mediators of these interactions would produce different "versions" of the public - e.g. actively engaged partners in dialogue vs. passive future users. From this perspective the openness and diversity of mediation projects deliberately employed by the Dutch nanotechnology debate are interesting. Conley (2011) extends the concept by arguing that scientists should also be prepared in order to become good "engagement agents".

A significant part of the Dutch nano-debate revolved around enabling imagination (or visualisation) in order to enable society to understand in concrete ways the impact of science 
and technology on their lives. Indeed, in the instance of the Dutch debate, public reaction became more nuanced after the provision of information and the preparation for the debate (Swierstra et al., 2011).

In the case of a developing field of science or technology, preparation for a meaningful interaction with society becomes challenging, as the science/technology itself is still only manifest in "expectations, plans and promises" of stakeholders such as scientists, government, investors and others (Swierstra et al., 2011, op. cit.).

\subsection{Reflections on aspects of the organisation of participation}

There is inevitably a need for organisations to act as intermediaries and to facilitate these dialogues, thereby providing havens of confidentiality for scientists to engage without bearing the burden of the representation of interests (Bijker et al., 2010). A brief discussion of these intermediaries follows.

\subsubsection{Intermediary organisations}

The nature and role of intermediary organisations are considered significant and the role of the CieMDN has been described in Section 2 of this paper. Interestingly, in the instances studied for this paper, the organisations identified or created to be the intermediaries are not universities (although the CieMDN was governed by a majority of academics). The outputs of these organisations are actionable rather than scholarly, i.e. advisory reports rather than journal or conference papers. Such advisory reports are considered useful for policy formulation and can serve as a basis for discussions in a political context (Bijker et al., 2010).

The notion of reason as the ultimate basis for selecting views or arguments remains central to the notion of deliberative democracy. In this regard a risk that needs to be managed is the potential impact of unspoken expectations of sponsors (i.e. significant stakeholders that play roles in defining the structure and processes of the interactions) such as government or large players in industry (Lövbrand et al., 2010).

An important aspect of the role played by the mediating organisation is the preservation of ambiguity. The future direction of science and technology, being a social construct, is not pre-determined and can only be expressed as a series of imagined scenarios. These need to be managed not to go to extremes ("bype" vs. "horror") (Swierstra et al., 2011). In this regard an example of undemocratic behaviour in these mediating organisations is provided by Volonté (in Bijker et al., 2010) who recounts that CieMDN orchestrated aspects of the Dutch nanodebate by sourcing opposing expert scientific opinions in instances where there was a feeling that contributions by scientific experts in a certain area were unbalanced. The mediating body's implied imposition of values and norms regarding public participation has been argued to be problematic, as it could impact on the whole notion of public participation (Van Oudheusden, 2011).

\subsubsection{Sponsoring organisations: The example of the "Gezondheidsraad"}

I want to pause briefly to reflect on the Gezondheidsraad, because it is central to the interactions between scientists and society in the Netherlands. It is the body that by law is mandated to provide scientific advice to government, and in fact it is largely because of the recommendation of the Gezondheidsraad amongst others that the nanodebate was undertaken in the Netherlands. It does its work through committees that largely consist of academics from the Netherlands and abroad.

Bijker et al. (2009b) go to pains to explain the complex nature of the Dutch Gezondheidsraad. The organisation varies in focus, composition, size of network involved, 
boundaries and temporality of the scientific information collated and provided to stakeholders. It is independent of government and allows for confidentiality in scientific discourse. It makes scientific knowledge accessible for social engagement and use (Ibid.) Above all, the authors stress that it has retained scientific authority in an era where this authority has become eroded. Its role is mainly to imbue its societal initiatives with authority - something that Bijker et al. (2009b, op. cit.) consider to be an interesting paradox in an age where scientific organisations have largely lost authority within society. A comparative organisation exists in the USA - the US National Academy of Sciences.

An important aspect of these organisations is space they provide for debate amongst scientists and other experts. Notable in this regard is the premium placed on the confidentiality of these deliberations (Bijker et al., 2010; Bijker et al., 2009b). The confidentiality is intended to allow robust debates around scientific controversies without the need to publicly represent any established interests. It also aims to allow for a suitable translation of science in a way that makes it accessible for society. (In a sense this renders these organisations effectively undemocratic). This adherence to confidentiality could be contrasted to the many voices in literature calling for a complete openness to all of science, scientific objects and structures (Bijker et al., 2010).

\subsubsection{The role of government}

Government inevitably plays a significant role in science-society interaction. The nature of the involvement of government includes the legislation that brings into being organising bodies and sponsoring organisations such as the Gezondheidsraad or the US National Academy of Sciences (Bijker et al., 2009b), even though care is taken to ensure that these ultimately operate independently. Government ultimately creates the policies that govern responsible use of science and technology. Similarly, policy is seen as one of the main instruments to regulate the outcomes of the negotiations between science and society (Bijker et al., 2010) and to govern the responsible use of science and technology.

Society inevitably expects government to play a significant role in managing risk. One of the recommendations emanating from the Dutch nanotechnology dialogue was that government should show visible commitment to society to enforce the "agreement" between society and science (Swierstra et al., 2011).

\subsubsection{Specific risks and issues in the process of participation that need to be managed}

If the processes followed in science-society interactions are completely divergent with no standard to evaluate the legitimacy of the responses to these interactions, there is no guarantee that the outcomes of these processes are better than it would have been if any other process (or indeed no process) had been followed (Lövbrand et al., 2010).

There is a potential impact of unspoken expectations of sponsors such as government or large players in industry that needs to be managed (Lövbrand et al., 2010). The need for rational argument and collaborative participation is therefore not necessarily universally shared by participants in the reality of science-society engagement. Personal expression of power, modes of communication and structural cultural and other constricting factors may indeed play a significant role (Van Oudheusden, 2011). 


\section{The impact of science-society interaction on science and scientific activity}

\subsection{The re-conceptualisation of scientific activity}

The "standard view of science" (Bijker et al., 2009b) (or Information Deficit Model, as previously mentioned) is not compatible with the socialization of science. This essentially binary view entails that method is everything and that good science can be clearly distinguished from bad science (and concurrently that scientists are clearly separated and distinguishable from non-scientists) (Ibid.). Essentially, as facts are "indisputable", it implies a "one-way" engagement between science and society, with science providing the solid factual basis on which society can proceed. Furthermore this view does not require science to be normative, as facts (with nature as the impartial judge of their accuracy) are neutral. The traditional view assumes that only scientists can make pronouncements regarding scientific matters (Kleinman, 1998).

Instead, scientific activity has become recognised as being socially constructed. This has been one of the core arguments of the Science and Technology Studies (STS) discourses amongst sociologists of science (Bijker et al., 2010) for a number of decades. In fact, Stengers (2011) implies that science is not only socially constructed, but there is even space for the course of science to be influenced by social advocacy. Recognizing the social construction of science and technology raises the argument that there would be little to distinguish scientific knowledge from other socially constructed types of knowledge, and that therefore the importance of scientific knowledge has become downgraded (Bijker et al., 2010). Issues regarding the cornerstones of scientific knowledge (such as its peer review processes) create further concerns about the nature of scientific knowledge - even within the scientific community (De Beer and Roux, 2010) - and contribute to the dilemma of how to distinguish scientific knowledge from other types of knowledge.

Recognizing the social nature of science also means that the conceptualisation of a binary relation between the scientist and the member of society is replaced with a notion of a social network of actors involved in the activities of science and influencing its direction and outcomes - see for instance Latour (2004). The functionality of boundaries is also redefined. Instead of being seen as a separation, a boundary becomes a zone of co-ordination (e.g. between science and politics) (Bijker, 2009 on the role of scientific advising) resulting in "linking up various domains" (Bijker et al., 2009b).

Bijker (2009, op. cit.) argues strongly for a conceptualisation of science as a societal enterprise. He indicates that such a conceptual shift would result in the adoption of more useful metaphors than those currently employed in the discussion of interaction between scientists and society. The example he provides, is that there should be a shift from the notions of "quantification, optimization and management" to, for instance, the notion of "vulnerability", which resonates more closely with the human condition.

Furthermore, as facts are no longer indisputable but instead are social constructs (Bijker et al., 2010), and scientists are correspondingly no longer undisputed authorities on science in society, science inevitably needs to become normative and has to reflect on the ethics of its activities that produce the knowledge constituting its outcomes. This is arguably a relatively uncontroversial outcome of the engagement between science and society (potentially more controversial outcomes are pointed out in sections 4.2 and 5 of this paper). 
4.2 The potential extent of societal interaction with scientific activity and the modes of interaction available to society

The outcome of the engagement processes in terms of impacting on scientific activity appears to be indirect, rather than direct - for instance, through impacting on policy formulation that regulates scientific behaviour (Kleinman, 1998).

However, Kleinman (op. cit.) provides evidence of a spectrum of potential levels of engagement by society with science. For instance, engagement on ethics, values and priorities as "soft issues" are fairly widely accepted and practiced in various countries. Engagement by society on scientific methods, the production of scientific knowledge and the evaluation of this knowledge could be considered contentious and could well meet with some resistance by scientists. However, it might hold more significant potential in terms of the reform of scientific knowledge argued for by for instance De Beer and Roux (2010). These potential areas of engagement are summarised in Table 1.

\begin{tabular}{|c|c|c|}
\hline & $\begin{array}{l}\text { Direct influence by the society on } \\
\text { scientific activity }\end{array}$ & $\begin{array}{l}\text { Indirect influence by society on } \\
\text { scientific activity }\end{array}$ \\
\hline $\begin{array}{l}\text { Potential "hard" involvement } \\
\text { [more drastic and possibly more } \\
\text { controversial] }\end{array}$ & $\begin{array}{l}\text { Examples: } \\
\text { Prescriptions to scientists regarding } \\
\text { methods } \\
\text { Participation in knowledge creation } \\
\text { Participation in the evaluation of } \\
\text { knowledge through more extensive } \\
\text { peer review processes } \\
\text { Citizen-initiated science projects } \\
\text { Societal participation in setting the } \\
\text { agendas for core scientific activity }\end{array}$ & $\begin{array}{l}\text { Examples: } \\
\text { Policies on methods and knowledge } \\
\text { generation } \\
\text { Statutory requirements for scientific } \\
\text { methods, practitioners, access to the } \\
\text { scientific domain } \\
\text { Creation of } \\
\text { organisations/bodies that contribute } \\
\text { to and influence science and scientific } \\
\text { practice }\end{array}$ \\
\hline $\begin{array}{l}\text { Potential "soft" involvement } \\
{[\text { less drastic and more socially }} \\
\text { acceptable }]\end{array}$ & $\begin{array}{l}\text { Examples: } \\
\text { Citizen participation in scientific } \\
\text { boards deliberating on ethics, values } \\
\text { and social impact of science on society } \\
\text { Citizen participation in scientific } \\
\text { boards providing requirements and } \\
\text { priorities of society that science needs } \\
\text { to meet } \\
\text { Society-involved participation in } \\
\text { setting the agenda for soft issues } \\
\text { related to scientific activity }\end{array}$ & $\begin{array}{l}\text { Examples: } \\
\text { Policies on ethics and values } \\
\text { Structures of mediation between } \\
\text { science and society } \\
\text { Agency related to structures of } \\
\text { mediation }\end{array}$ \\
\hline
\end{tabular}

Table 1: Schematized view of potential societal involvement in science (Adopted and expanded on the basis of the basic categories of Kleinman, 1998)

\section{Intelligence as a cultural-historical phenomenon}

What remains, is to consider the notion of intelligence and its potential tension points (battle fields), as these relate to science-society interaction and to scientific activity.

I would argue that a conceptualisation of intelligence that is compatible with the notion of a socially constructed scientific enterprise should be the point of departure. In addition, I would argue for a notion of intelligence that is more than simply a metaphoric transfer of the notion of individual cognitive capability to a societal level. Such a notion should allow for a 
systemic consideration of intelligence in relation to the interaction between science and society.

I propose that the notion of a distributed intelligence (also sometimes referred to as distributed cognition) embedded in cultural-historical activity approaches, offers such an option. This notion of distributed intelligence has been applied mainly in educational context to conceptualise, for instance, education design (Pea, 1993) and distributed leadership in education (Spillane et. al., 2004). Engeström et al. (1995) have applied this notion to the work and activity of experts in settings such as local government and factories.

By applying the notion of distributed work-based intelligence to scientific activity and its interaction with society, a conceptualisation can be created of potential tension points and uncertainties (risks) associated with societal interaction with the work of scientists. This is set out in the following paragraphs.

Cole and Engeström (1993) argue that intelligence has always been considered by psychologists to be distributed/collective in nature (since Wundt). They point out that even Wundt argued that the cognitive functioning of individuals can only be understood in the context of "historical contingent phenomena" that are not amenable to scientific experimentation (Cole and Engeström, op. cit.; Mischel, 1970). This is in contrast to the widely held conception of intelligence as residing primarily in the minds of individuals (Pea, 1993).

The notions regarding human activity systems and cognition were originally developed by Russian social psychologists (see Vygotsky, 1980; Leont'ev, 1978) as part of understanding human activity systems in the context of historical cultural activity. Ultimately activity theorists argue that the loci of human cognition are visible only in human activity (Pea, 1993). The diagram in Figure 1 shows a schematic representation of a human activity system.

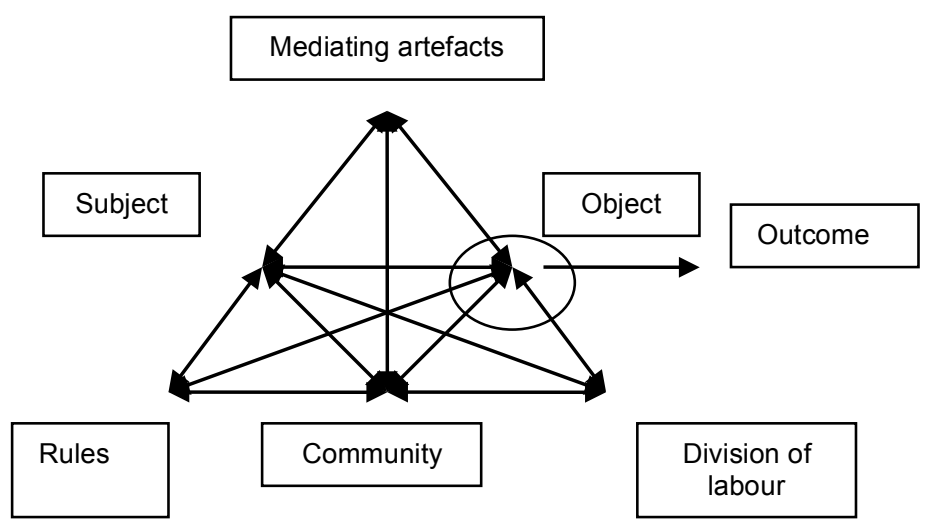

Figure 1: Conceptualisation of the structure of human activity (Adopted from Engeström, 2001)

The schematic representation in Figure 1 shows the main elements of any human activity system. These include the traditional main elements in the Vygotskian tradition of a subject interacting with an object through mediating artefacts in order to achieve an outcome, which inevitably is some transformation of the object. Later additions by activity theorists relate to an enabling context for these main elements. The elements of the enabling context constitute 
the rules, communities and division of labour that support the activities taking place. Cultural-historical activity theory assumes a large-scale stability or slow evolution of activity systems (Engeström, 2001) through the resolution of tensions and stresses inherent in the activity system.

In terms of the conceptualisation of science-society interaction (and of science itself) as socially constructed, it can be argued that this conceptualisation of an activity system would also be applicable to these areas of human activity.

This conceptualisation assumes intelligence to be expressed as action, rather than as astate of being" (Pea, 1993). Pea (op. cit.) describes this type of intelligence as follows:

The focus in thinking about distributed intelligence is not on intelligence as an abstract property or quantity residing in the minds, organizations or objects. In its primary sense here, intelligence is manifest in activity that connects means and ends through achievements (Pea, 1993: 50).

The various elements of the activity system may be considered to be stabilised expressions of intelligence, demonstrating activity-based "patterns of distributed intelligence" (Ibid.). The person does not disappear, but the boundaries between the person and human activity are more diffuse. This representation highlights external expressions of intelligence within the human activity system.

Similarly, intelligence-related tensions could be associated with any of the elements or between elements that would obstruct the manifestation of intelligent connections between means and ends - these typically constitute the manifestation of intelligence-related "battles" over the interaction between science and society (and ultimately also reflecting on scientific activity) referred to in the introductory paragraphs of this paper.

Some examples of potential intelligence-related tensions in science-society engagement becoming visible in terms of an activity system are listed in Table 2.

\begin{tabular}{|l|l|}
\hline $\begin{array}{l}\text { Element of human activity } \\
\text { system for science-society } \\
\text { engagement }\end{array}$ & $\begin{array}{l}\text { Example of potential tensions in science-society interaction (drawn from } \\
\text { earlier arguments in this paper) }\end{array}$ \\
\hline $\begin{array}{l}\text { Object and its } \\
\text { transformation }\end{array}$ & $\begin{array}{l}\text { Discourses around priorities, objectives and risks of scientific endeavour for } \\
\text { society }\end{array}$ \\
\hline Tools & Diversity vs. non-diversity of engagement mechanisms \\
\hline Subject & Credibility of organisations initiating society-science interactions \\
\hline Rules & $\begin{array}{l}\text { Role of experts } \\
\text { Transparency of deliberations vs. confidentiality } \\
\text { Final decision on validity of outcomes of science-society interaction }\end{array}$ \\
\hline Division of labour & Final arbiter on validity of outcomes of science-society interaction \\
\hline Communities & $\begin{array}{l}\text { Vested interests and power bases of selected communities involved in science- } \\
\text { society interaction } \\
\text { Representativeness vs. non-representativeness of participatory groups from } \\
\text { society }\end{array}$ \\
\hline
\end{tabular}

Table 2: Examples of potential tensions in a human activity system for sciencesociety engagement

Examples of intelligence-related tensions externally expressed in the considered human activity system for scientific activity resulting from science-society engagement, are listed in Table 3. 


\begin{tabular}{|l|l|}
\hline $\begin{array}{l}\text { Element of human activity } \\
\text { system for scientific activity }\end{array}$ & $\begin{array}{l}\text { Example of potential tensions in scientific activity (drawn from previous } \\
\text { arguments in this paper) }\end{array}$ \\
\hline Object and its transformation & $\begin{array}{l}\text { Society and science may differ on the objectives, priorities and direction of } \\
\text { science, which would then need to be debated. }\end{array}$ \\
\hline Tools & $\begin{array}{l}\text { Traditional tools of scientific knowledge production vs. new tools (e.g. } \\
\text { expanded peer review mechanisms) }\end{array}$ \\
\hline Subject & $\begin{array}{l}\text { Traditional scientists engaging with scientific knowledge creation vs. } \\
\text { expanded notions of the subjects of scientific knowledge creation }\end{array}$ \\
\hline Rules & $\begin{array}{l}\text { Managing science as a business vs. managing science as a societal project } \\
\text { Establishing of stable "rules" governing science-society interactions as well as } \\
\text { rules regarding the evaluation of quality of interactions. } \\
\text { Confidentiality of scientific discourse vs. transparency of all engagements }\end{array}$ \\
\hline Division of labour & Society having a share in the evaluation of scientific knowledge \\
\hline Communities & $\begin{array}{l}\text { Exponents of the traditional view of science vs. novel views } \\
\text { Communities with vested interests }\end{array}$ \\
\hline
\end{tabular}

Table 3: Examples of potential tensions in a human activity system for sciencesociety interaction

\section{Conclusions}

Engagement between science and society holds the potential for science to expand its base and context, and for society to reduce the uncertainties associated with the impact of scientific activity on society.

The intrusion of public participants into spheres which until fairly recently have been considered the exclusive domain of scientists (Kleinman, 1998), does not in itself pose a threat to intelligent scientific practice. In fact, it allows science to exit Stenger's (2011) "groove" by widening the scientific discourse from one limited to participation by scientists and like-minded parties elsewhere in society, to one that involves diverse societal participation (which has the beneficial potential of slowing down science).

Science-society interaction could support the initiation of some of the mechanisms proposed by De Beer and Roux (2010) for improving the evaluation of scientific knowledge. For instance, it could allow for more extensive peer evaluation of scientific results than simply evaluation by other like-minded scientists and interest groups - thus moving closer to the notion of an "ecology of peer review". In addition, science-society interaction resonates strongly with the notion of discursive practices at an early stage of scientific endeavour.

Finally, it has the potential to make scientific activity more visible and transparent.

A cultural-historical perspective of intelligence allows for a systematic envisioning of the manifestation of tensions in the human activity systems that comprise science-society interaction and socially constructed scientific activity - thus allowing for a systematic understanding of the "battles for intelligence" that would potentially be involved in the evolution of these systems. 


\section{References}

Barry, A. (2001). Political Machines: Governing a Technological Society. London: The Athlone Press.

Bijker, W.E. (2009). Vulnerability in Technological Cultures. Diësrede 2009: Address at the occasion of the $33^{\text {rd }}$ Anniversary of Maastricht University, January $8^{\text {th }} 2009$.

Bijker, W.E. (2010). How is technology made? - That is the question! Cambridge Journal of Economics, 34, $63-76$.

Bijker, W.E., and Andrea, L. (Eds.) (2009a). Handbook on the socialisation of scientific and technological research. Rome: River Press Group.

Bijker, W.E., Bal, R., and Hendriks, R. (2009b). The Paradox of Scientific Authority - the Role of Scientific Advice in Democracies. The MIT Press, Cambridge, MA.

Bijker, W.E., De Beaufort, I.D., van den Berg, A., Borm, P.J.A., Oyen, W.J.G., Robilllard, G.T. and van Dijk, H.F.G. (2007). A response to 'Nanotechnology and the need for risk governance', O. Renn \& M.C. Roco, 2006. J. Nanoparticle Research 8(2): 153191, Journal of Nanoparticle Research, 9:1217-1220.

Bijker, W.E., Volonté, P. and Grasseni, C. (2010). Technoscientific Dialogues - Expertise, Democracy and Technological Cultures. Technoscienza - Italian Journal of Science and Technology Studies, 1(2) pp. 121 - 140.

Cole, M. and Engeström, Y. (1993). A cultural-historical approach to distributed cognition. In G. Salomon (Ed.) Distributed cognitions: Psychological and educational considerations. Cambridge: Cambridge University Press.

Commissie Maatschappelijke Dialoog Nanotechnologie (CieMDN). (2011). Verantwoord verder met nanotechnologie: Bevindingend maart 2009 - januari 2011. Den Haag.

Conley, S.N. (2011). Engagement agents in the making: On the front lines of SocioTechnical Integration. Science Engineering Ethics, 17: 715 - 721.

De Beer, F. and Roux, B. (2010). Onderweg na goeie wetenskap. Ewekniebeoordeling: betroubare weegskaal of vyfde wiel aan die wa? Litnet Akademies 7(2).

De Raath, J.D.R. (1997). A sketch for humane operational research in a technological society. Systems practice, 10(4): $421-441$.

Engeström, Y. (2001). Expansive learning at work: toward an activity theoretical reconceptualisation. Journal of education and work, 14, 133-155.

Engeström, Y., Engeström, R. and Kärkkäinen, M. (1995). Polycontextuality and Boundary Crossing in Expert Cognition: Learning and Problem Solving in Complex Work Activities. Learning and Instruction, 5: $319-336$.

Kleinman, D.L. (1998). Beyond the science wars: Contemplating the Democratization of Science. Politics and the Life Sciences, 16(2): 133-145.

Latour, B. (2004). Politics of Nature - how to bring the Sciences into Democracy. Cambridge MA: Harvard University Press. 
Leont'ev, A.N. (1978). Activity, consciousness and personality. Englewood Cliffs: Prentice Hall.

Lövbrand, E., Pielke, R., and Beck, S. (2010). A Democracy Paradox in Studies of Science and Technology. Science Technology and Human Values.

Mischel, T. (1970). Wundt and the Conceptual Foundations of Psychology. Philosophy and Phenomenological Research, 31(1): 1-26.

Mohr, A. (2011). Publics in the making: Mediating different methods of engagement and the publics these construct. Science Engineering Ethics, 17: 667 - 672.

Nowotny, H. (2003). Dilemma of expertise: Democratising expertise and socially robust knowledge. Science and public policy, 30(3): $151-156$.

Pea, R.D. (1993). Practices of distributed intelligence and designs for education. In Gavriel Salomon (Ed.) Distributed Cognitions Psychological and Educational Considerations. Cambridge: Cambridge University Press.

Petersen, A.C., Cath, A., Hage, M., Kunseler, E., and Van der Sluis, J.P. (2011). PostNormal Science in Practice at the Netherlands Environmental Assessment Agency. Science, Technology \& Human Values, 36(3): 362 - 388.

Spillane, J.P, Halverson, R. and Diamond, J.P. (2004). Towards a theory of leadership practice: A distributed perspective. Journal of curriculum studies, 36(1): 3-34.

Stengers, I. (2011). "Another science is possible!" A plea for slow science. Inaugural lecture Chair Willy Calewaert 2011-2012 (VUB).

Swierstra, T., Van de Wijngaert, L., and Hilbrink, A. (2011). Het Grote Nano-Onderzoek Publieksonderzoek naar de gevolgen van nanotechnologie. Resultaten van de statistische analyse. Nanopodium.

Te Kulve, H. and Rip, A. (2011). Constructing Productive Engagement: Pre-engagement Tools for Emerging Technologies. Science Engineering Ethics, 17: 699 - 714.

Turnpenny, J., Jones, M. and Lorenzoni, I. (2011). Where now for post-normal science? A critical review of its development, definitions and uses. Science Technology Human Values, 36(3), 287 - 306.

Van Est, R. (2008). The Broad Challenge of Public Engagement in Science. Commentary on: "Constitutional Moments in Governing Science and Technology", Science and Engineering Ethics, 17: 639 - 648.

Van Oudheusden, M. (2011). Questioning 'Participation': A Critical Appraisal of its Conceptualisation in a Flemish Participatory Technology Assessment. Science and Engineering Ethics, 17: 673 - 690.

Vygotsky, L.S. (1980). Mind in society: The Development of Higher Psychological Processes. Harvard University Press.

Winner, L. (1992). Democracy in a technological society. Springer Science \& Business Media, Vol. 9. 